\title{
Effects of UV-B radiation on embryonic, larval and juvenile stages of North Sea plaice (Pleuronectes platessa) under simulated ozone-hole conditions
}

Received: 4 December 1999 / Received in revised form: 20 April 2000 / Accepted: 3 May 2000 / Published online: 6 February 2001 C) Springer-Verlag and AWI 2001

\begin{abstract}
Irradiation with artificial quasi-solar light was used to investigate lethal and sublethal effects of enhanced ultraviolet-B (UV-B) radiation on eggs, larval and juvenile stages of North Sea plaice. The irradiation experiments resembled a worst-case scenario with a synchronous occurrence of ozone depletion, sunny weather, and low water turbulence. In eggs, UV-B exposure increased mortality and induced loss of positive buoyancy. UV-B exposures for 1 or 2 days, according to the weather conditions in spring, impaired eggs only if UV-B intensities and doses exceeded those under a further $60 \%$ ozone loss. In larvae and juveniles, long-term UV-B exposures during and after metamorphosis affected ventilation rate at normoxia and ventilatory regulation during hypoxic incubations. Oxygen consumption rates of juveniles were not affected by UV-B irradiation.
\end{abstract}

Keywords Ultraviolet-B · Ozone depletion · Flatfish · Development $\cdot$ Pleuronectes platessa

\section{Introduction}

Current measurements of stratospheric ozone levels have revealed the lowest values observed so far. The loss of total column ozone and the related enhancement of solar ultraviolet-B (UV-B) radiation $(280-315 \mathrm{~nm})$ is now thought to be close to its maximum, causing a wide range of deleterious effects on the biosphere. The recovery of the ozone layer will take several decades even under the most optimistic assumptions (UNEP 1998).

In the marine environment, harmful UV-B rates are encountered by organisms of the euphotic zone, including developmental stages of various fish species of so-

Communicated by K Lüning

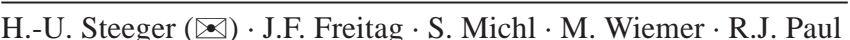
Institut für Zoophysiologie, Westfälische-Wilhelms-Universität, Hindenburgplatz 55, 48143 Münster, Germany e-mail: steeger@uni-muenster.de

Tel.: +49-251-8323868, Fax: +49-251-8323876 cio-economic importance (Smith 1989; Häder and Worrest 1991; Häder et al. 1995; Davidson 1998; Häder et al. 1998). The amount of UV-B radiation which reaches the water surface and penetrates into the water column is governed by a range of environmental conditions. Besides total column ozone, parameters with high natural variability like cloud cover, aerosol quantity and absorbance in the water column determine the UV-B stress at a given water depth (Smith and Baker 1979; Németh et al. 1996). Thus, a precise prediction of the UV-B levels encountered by marine organisms is difficult.

A common approach with which to assess the effects of UV-B in a first approximation is to irradiate organisms by artificial light sources with a spectral composition near to the solar spectrum. Effects of UV-B are then revealed by comparing the UV-B-irradiated group with a control group, which is protected by UV-B-absorbing filters. In combination with a constant daily irradiation scheme, this experimental set-up rules out any of the fluctuating natural parameters, which generally attenuate UV-B intensity. As a result, the experiment resembles a worst-case scenario and must be interpreted carefully with respect to natural UV-B stress. However, with this set-up it is possible to investigate the effects of the UV-B increase under standardized conditions.

Effects of UV radiation on fish offspring, namely increased mortality, have been reported by Haempel and Lechner (1931), Hamdorf (1960) and Pommeranz (1974). Epidermal lesions (sunburn) and/or fungal infections were reported in coho salmon (Oncorhynchus kisutch) fry (Bell and Hoar 1950) and rainbow trout (Oncorhynchus mykiss) fingerlings (Dunbar 1959). Investigations of UV-B effects on eggs or larvae have been intensified after the discovery of the Antarctic ozone hole: larval anchovy (Engraulix mordax) exhibited a reduction of survival and growth rate (Hunter et al. 1979; Kaupp and Hunter 1981; Hunter et al. 1981). Applegate and Ley (1988) found an induction of pyrimidine dimers in DNA and a concomitant increase in mortality in embryos of fathead minnow (Pimmephales promelas). Acute mortality, malformations and loss of positive 
buoyancy in eggs of plaice (Pleuronectes platessa) and dab (Limanda limanda) were reported by Dethlefsen et al. (1996). In a study by Steeger et al. (1999), UV-B reduced the survival of plaice embryos only if the irradiation commenced before gastrulation. Applied after gastrulation, UV-B irradiation had no effect on mortality. A particular high mortality in eggs of the Atlantic cod (Gadus morhua) irradiated early in embryogenesis was also found by Kouwenberg et al. (1999). Under high experimental doses, UV-B reduces the daily increase in heart rate during embryonic development (Steeger et al. 1999). In plaice larvae, UV-B impairs the development of respiratory control during ontogenesis (Freitag et al. 1998). In plaice juveniles, sunburn damage was detected by Berghahn et al. (1993) and induction of hyaline zones in otoliths was reported by Berghahn and Karakiri (1990).

In the present study, plaice was chosen as a test organism for UV-B impairment because of its commercial importance and the fact that it could be endangered by UV-B radiation during its development. Plaice spawn in the winter season, when the largest negative ozone trends were observed in the northern hemisphere (Niu et al. 1992). Spawning begins in the Western Channel in December, proceeds in the Southern Bight and Transition Area during February and ends in the German Bight and Fisher Bank at the end of March (Hovenkamp 1991). Exposure of certain developmental stages to solar light and elevated UV-B intensities can then be expected in three cases:

1. Eggs of plaice are positively buoyant and float at the water surface in the case of calm weather (Hempel and Weikert 1972). They are not pigmented and their period of development until hatching is comparably long; approximately 18 days at $6^{\circ} \mathrm{C}$ (von Westernhagen 1970). At the spawning grounds in the open sea, the UV-B attenuation of the water is low, and exposure to this stage is governed almost exclusively by the weather conditions and total column ozone.

2. Until the onset of metamorphosis, plaice larvae exhibit positive buoyancy as well. Although they show a certain swimming activity, they are still found in the upper water layer. The larvae are only poorly pigmented at the time of hatching and slowly increase their pigmentation until metamorphosis. During their drift to the nursery grounds, they gradually approach coastal water with increasing UV-B attenuation. The time between hatching and 50\% metamorphosis takes about 66 days at the usual water temperature (Ryland 1966).

3. During metamorphosis, plaice larvae invade the nursery grounds of the Wadden Sea and start to live as benthic animals. Juveniles can then be found in residual channels and shallow tide pools. Although the UV$\mathrm{B}$ attenuation is high in these waters, tide pools may only be a few centimetres deep. Exposure to increased solar UV-B radiation is further restricted to times of low tide around noon time. However, UV-B can be an additional environmental stress factor in this habitat, which is already characterized by extreme changes in physico-chemical parameters, namely water temperature, salinity, partial pressures of oxygen $\left(\mathrm{PO}_{2}\right)$ and carbon dioxide as well as $\mathrm{pH}$ (Truchot and DuhamelJouve 1980; Morris and Taylor 1983; Bridges et al. 1984; Berghahn et al. 1993).

The present study aimed at the investigation of UV-B effects in all three cases, namely on embryonic, larval and juvenile stages of the plaice. The UV-B-irradiation conditions (intensities and doses) were chosen with respect to present UV-B levels at the Wadden Sea coast and the time of occurrence of the certain developmental stages during the year. Besides the recording of mortality or survival, respectively, emphasis was laid on the detection of physiological, sublethal effects of UV-B at any developmental stage: loss of positive buoyancy in eggs, regulation of ventilation frequency (VF) in larvae and juveniles and oxygen consumption in juveniles.

\section{Materials and methods}

\section{Animals}

Fertilized plaice eggs (Pleuronectes platessa L.) were obtained from the Netherlands Institute for Sea Research (Texel, The Netherlands) or from Port Erin Marine Laboratory (Isle of Man, United Kingdom) and kept in artificial sea water prepared from tap water and synthetic sea salt (Wiegandt, Krefeld, Germany) The water with a salinity of $34.5 \pm 0.5 \%$ was gently aerated with room air and showed a $\mathrm{pH}$ of $8.2 \pm 0.1$. Water temperature was kept constant at $10 \pm 0.5^{\circ} \mathrm{C}$ and the light/dark regime was set at $12 \mathrm{~h} / 12 \mathrm{~h}$. The animals were raised in 12-1 black polyethylene buckets until metamorphosis was complete. Then the juvenile plaice were transferred to 100-1 containers. Larvae and juveniles were fed with freshly hatched nauplii of Artemia salina, which were renewed once a day. Larvae of the flounder (Platichthys flesus) were caught with a hand-towed plankton net $(300 \mu \mathrm{m})$ in a residual channel of the mudflats north of the Marine Biological Station Carolinensiel $\left(53^{\circ} 42^{\prime} \mathrm{N} ; 7^{\circ} 45^{\prime} \mathrm{E}\right)$ and kept as described above.

\section{UV-B irradiation}

Plaice eggs, larvae and juveniles were exposed to light from a set of fluorescent tubes with spectral compositions similar to sunlight in the UV range (Q-Panel UVA-340; Q-Panel Company, Cleveland, Ohio, USA) as well as in the visible range (Lumilux daylight L36 W/11; Osram, München, Germany). A detailed description of the irradiation set-up is given by Freitag et al. (1998). The effects of UV-B were assessed by comparing the UV-B-exposed group to a control group which was protected by Mylar foil. In the visible range of the spectrum, equal spectral intensity was achieved in both exposed and control groups by appropriate numbers of UV-B transparent perspex sheets (GS 2458; Röhm, Darmstadt, Germany). The spectral transmittances of the filter combinations were determined with a spectroradiometer (MMS UV-VIS spectrometer module; Zeiss, Oberkochen, Germany) relative to the solar spectrum. Experimental UV-B intensities could be controlled by adjusting the distance between animals and the light source. UV-B intensity was measured with a broad-band radiometer (IL 1400A; International Light, Newburyport, Mass., USA) equipped with a calibrated UV-B detector (250-320 nm; maximal sensitivity, $295 \mathrm{~nm}$; SEL 240/UVB/TD; International Light). Measured values were corrected with respect to the spectral filter characteristics of the detector. The applied UV-B intensities, daily dos- 


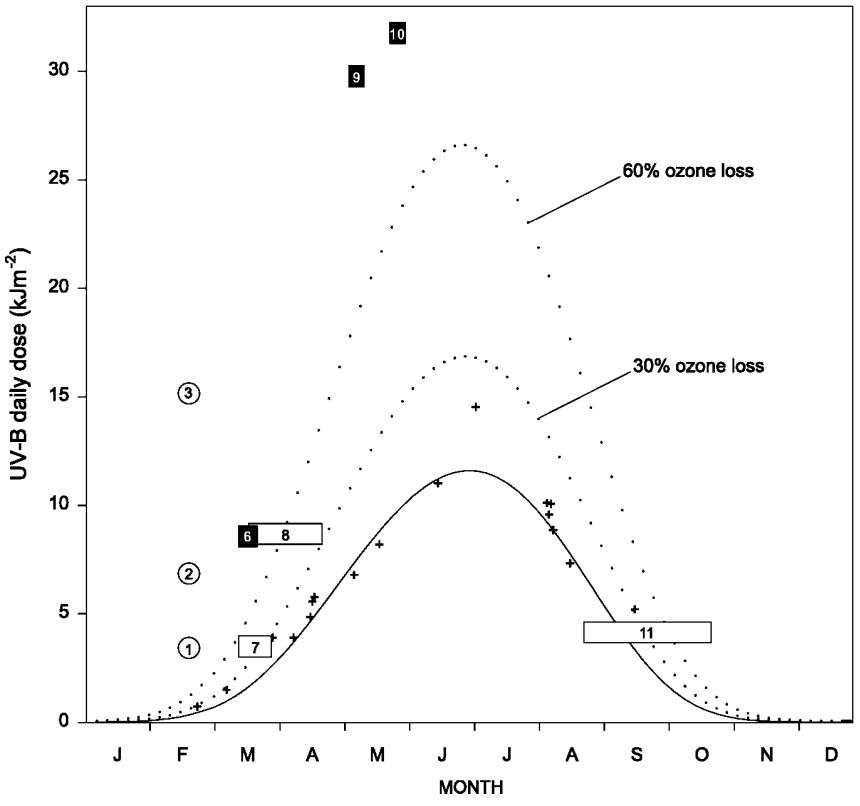

Fig. 1 UV-B exposure of developmental stages of the plaice (overview). In the years 1996 and 1997, solar UV-B daily doses were measured at Carolinensiel on clear days (crosses) and fitted to a curve of current ultraviolet-B $(U V-B)$ levels (solid line) as well as a further 30-60\% ozone depletion (dotted lines). The symbols represent developmental stages at the time of their occurrence in the habitat: eggs are represented by circles, larvae and juveniles by rectangles, whose sizes give an impression of the number of days with experimental UV-B irradiation. Black symbols indicate complete mortality of the UV-B-exposed test group as a direct result of UV-B exposure. The numbers correspond to Table 1, where further and less severe UV-B effects are summarized

es and accumulated doses were related to the UV-B scenario at the German Wadden Sea coast (Fig. 1). Maximal daily doses of UV-B, measured on clear days at Carolinensiel during the years 1996 and 1997 (crosses), were used to approximate the current UV-B doses for sunny weather during the year (solid line). Possible UV-B enhancements resulting from further ozone losses of $30 \%$ and $60 \%$ were calculated [after Björn (1989), dotted lines]. To study worstcase scenarios, the experimental UV-B levels exceeded the predicted UV-B increase for this latitude in some cases.

For the irradiation of eggs, sea water-filled 100-ml glass funnels were used. Each funnel contained about 100 eggs, from which subsamples of 30-40 individuals were taken after irradiation periods of $4.5 \mathrm{~h}, 9 \mathrm{~h}$ and twice $9 \mathrm{~h}$ on 2 consecutive days. The water in each funnel was renewed simultaneously. After the irradiation, eggs were divided into groups of five to six individuals and transferred to small jars. Twice a day, survival was determined by counting the number of eggs with positive buoyancy, and the water renewed. Larvae and juveniles were irradiated in black bowls made of polyethylene (diameter $25 \mathrm{~cm}$; height $6 \mathrm{~cm}$; height of water column $3 \mathrm{~cm}$ ) in a density of up to 20 individuals per bowl. The water in the jars was replaced once a day after the UV-B irradiation had stopped or, in the case of the experiments of 1996, replaced constantly by a recirculating flow-through system (wash out time $40 \mathrm{~min}$ for $90 \%$ exchange). All through the irradiation period, care was taken to provide freshly hatched nauplii of $A$. $s a$ lina in appropriate numbers once a day.

\section{Measurement of physiological parameters}

VF of larvae and juveniles was measured with a digital image processing device described in detail previously (Paul et al. 1997;
Freitag et al. 1998). Animals were gently fixed in a flow-through chamber of a video microscope and their ventilatory movements recorded digitally with a CCD camera. Pixel brightness changes due to opercular movements were recorded and analysed via FFT. The VF could thus be estimated every 3 or $6 \mathrm{~s}$. To investigate the accuracy of ventilatory responses to hypoxia, a test system based on a biocybernetical approach (Freitag et al. 1998) was used. The major task of the respiratory control system is to stabilize $\mathrm{Po}_{2}$ in tissues and body fluids at ambient $\mathrm{Po}_{2}$ variations by anti-phasic changes of VF: high VF at low ambient $P_{\mathrm{O}_{2}}$. The set-up modulated the ambient $\mathrm{PO}_{2}$ level in the flow-through chamber so that the curve was sine-shaped between normoxia and about $50 \%$ air saturation. Ambient $\mathrm{PO}_{2}$ was taken as the input signal of a control circuit and compared to the output signal, the evoked changes of VF. The application of sine-shaped $P_{\mathrm{O}_{2}}$ variations makes it possible to gain information about the linearity of signal transmission, i.e. the quality of respiratory control. Linear respiratory control will result in sine-shaped changes of ventilatory rate. Deviations (non-linearities) from such a response can be detected by Fourier analyses of the responses: the ratio of the amplitudes at the first harmonic and the fundamental frequency, the linearity quotient, was considered to indicate non-linear responses if its value exceeded 0.25 (Freitag et al. 1998).

Oxygen consumption of juvenile plaice was measured in a closed respirometer equipped with a Clark-type polarographic oxygen sensor (E5047, Radiometer, Copenhagen, Denmark). The animals were put into the respirometer chamber in the evening and left overnight to acclimate to the experimental conditions. During the acclimation period, the chamber was constantly flushed with normoxic water. In the morning, the water flow was stopped and the declining $\mathrm{Po}_{2}$ recorded until a $\mathrm{Po}_{2}$ of $0 \mathrm{kPa}$ was reached.

\section{Statistics}

Statements on the significance of differences met statistical criteria $(P \leq 0.05)$ of ANOVA or Student's $t$-test.

\section{Results}

Embryonic stages: mortality and loss of positive buoyancy

Mortality was recorded from the time the eggs were transferred to the irradiation device until first feeding of hatched larvae commenced (Fig. 2). Eggs which showed positive buoyancy were considered as alive. Loss of positive buoyancy in otherwise viable eggs was observed in some cases. Eggs which had sunk to the bottom but showed no sign of decomposition were left in the incubation device. A certain amount of these eggs gained back their positive buoyancy during the next days, hence leading to the paradox of a rising percentage survival with time (Fig. 2b2, d2, d3). Although loss of positive buoyancy was found in non UV-B-irradiated eggs as

Fig. 2 Percentage survival of plaice eggs following exposure to light either including UV-B (closed circles) or not (open circles). Positive buoyancy was taken as an indicator of survival. The UV$\mathrm{B}$ intensity is given with each graph, the total UV-B doses are indicated by dotted lines. Significant differences between survival rates of UV-B test group and the corresponding control group were tested by ANOVA and are marked with an asterisk. Time of hatching is shown by a bar marked with $H$ 
irradiated before gastrulation
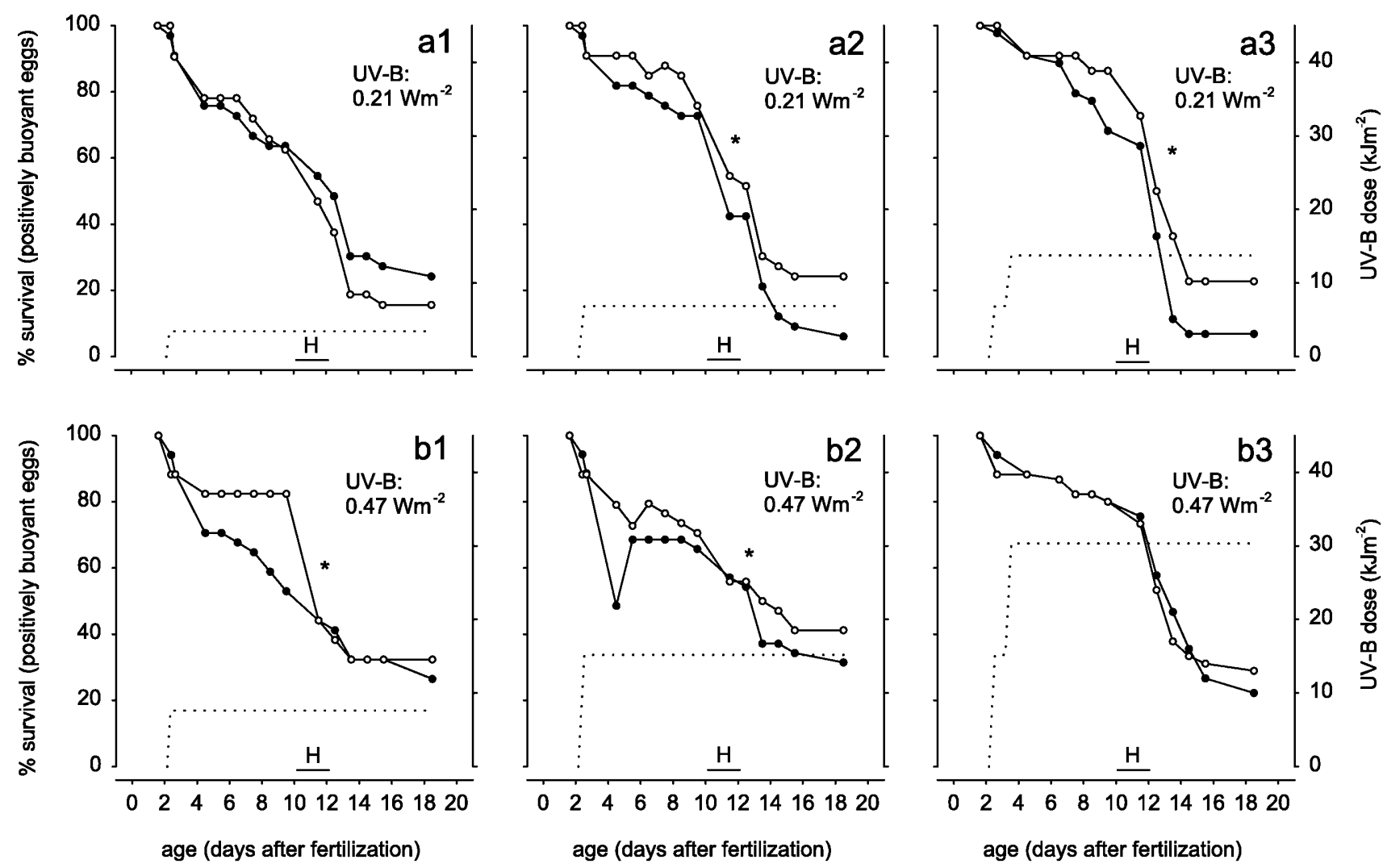

irradiated after gastrulation
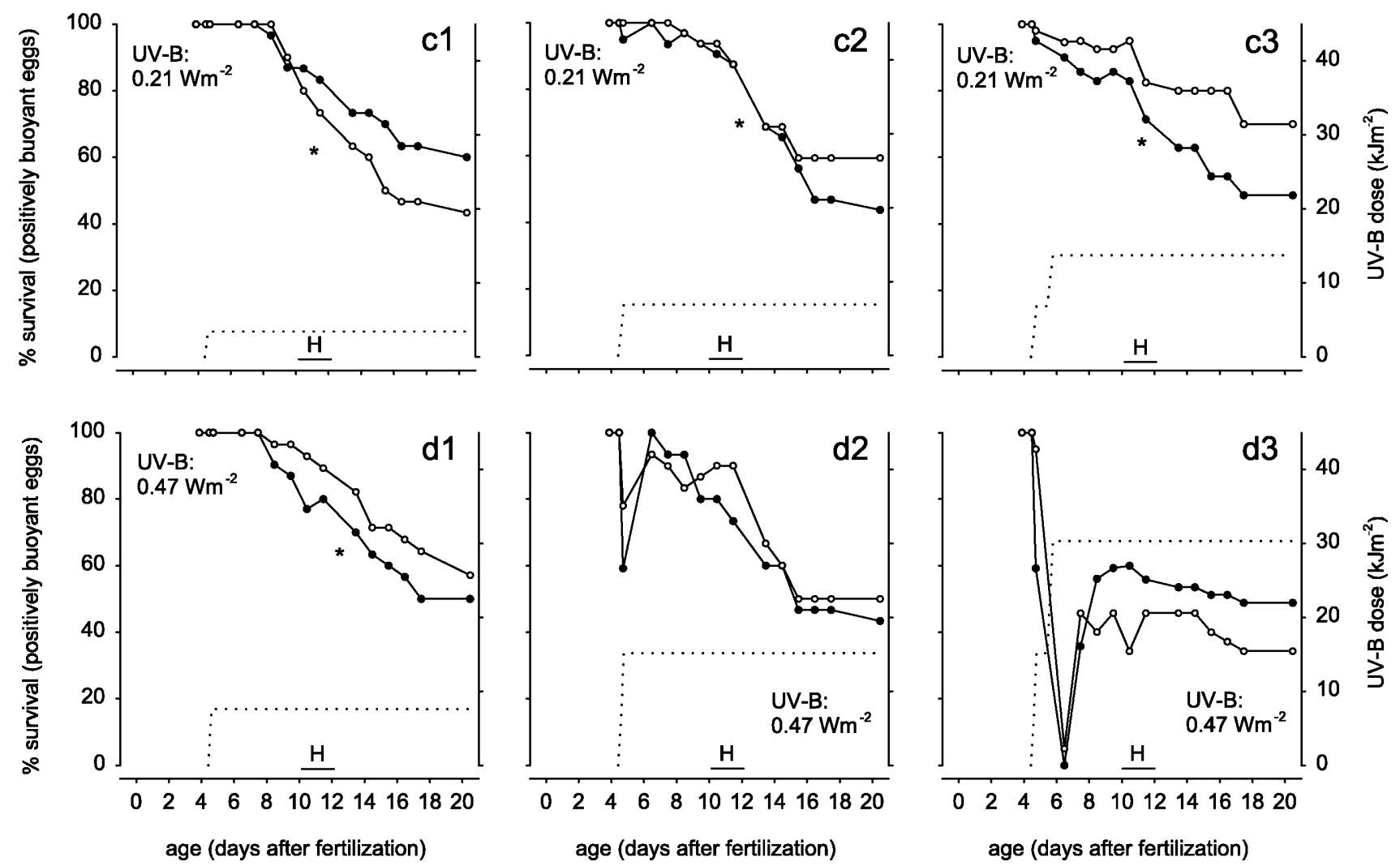
well, it was always more pronounced in the corresponding UV-B-irradiated groups.

In eggs transferred to the irradiation device before gastrulation a mortality of 10-30\% during the first days of incubation was observed. After gastrulation, the mortality was generally lower. In both eggs irradiated before gastrulation and eggs irradiated after gastrulation, the lowest UV-B intensity and dose $-0.21 \mathrm{Wm}^{-2}$ and $3.43 \mathrm{kJm}^{-2}$, respectively - resulted in a higher percentage survival of the UV-B-treated group compared to the group irradiated with light containing no UV-B (Fig. 2a1, c1). Higher UV-B intensities or doses, however, led to a higher mortality of the UV-B groups. The survival of plaice eggs irradiated with UV-B before gastrulation was 6-18\% lower than that of non UV-B-irradiated controls at day 18 after fertilization. Irradiated after gastrulation, the differences in mortality between UV-B-exposed eggs and not UV-Bexposed eggs ranged from $7-21 \%$ at day 20 after fertilization. A dependency of mortality on UV-B dose was not obvious. After treatment with the highest accumulated UV-B dose of $30.32 \mathrm{kJm}^{-2}$, the mortality rates of the corresponding groups were not significantly different (Fig. 2 b3, d3). This was obviously caused by reduced survival of the non UV-B-irradiated controls, possibly due to high UV-A doses in these experiments.

Larvae and juveniles: VF, respiratory control and oxygen consumption

UV-B levels with intensities and doses far exceeding those of the predicted ozone-loss scenario induced $100 \%$ mortality in plaice larvae and juveniles, and also in flounder larvae (see Fig. 1, closed rectangles). Lower and more realistic UV-B-irradiation conditions had no effect on mortality of plaice larvae or juveniles (see Fig. 1, open rectangles). Irradiation in these experiments started before metamorphosis and was continued up to 30 days. Measurements of physiological parameters were done successively, alternating control animals and UV-B-irradiated animals. The physiological parameters investigated were $\mathrm{VF}$ at normoxia and regulation of VF during sine-shaped modulations of the $\mathrm{PO}_{2}$ in the water. In plaice larvae not irradiated with UV-B a tendency for a decrease in VF with age was observed (Fig. 3, open symbols, solid line). Calculated for three consecutive age classes of 9 days each, the average VF was $100.4 \pm 16.0 \mathrm{~min}^{-1}$ at the age of $71.4 \pm 2.2$ days $(n=7), 104.7 \pm 18.7 \mathrm{~min}^{-1}$ at the age of $79.9 \pm 2.7$ days $(n=10)$ and $74.3 \pm 17.3 \mathrm{~min}^{-1}$ at the age of $88.0 \pm 2.8$ days $(n=7)$. In contrast, animals exposed to UV-B showed a slight increase in VF with time (Fig. 3, closed symbols, dotted line). Here, the average VF was $113.4 \pm 13.8$ at the age of $71.0 \pm 3.0$ days $(n=6), 103.4 \pm 20.1$ at the age of $79.7 \pm 2.8$ days and $114.8 \pm 9.5 \mathrm{~min}^{-1}$ at the age of $87.3 \pm 26$ days. In the oldest age class, mean VFs were significantly different between UV-B-irradiated and non UV-B-irradiated animals (Student's $t$-test, $P=0.00015$ ).

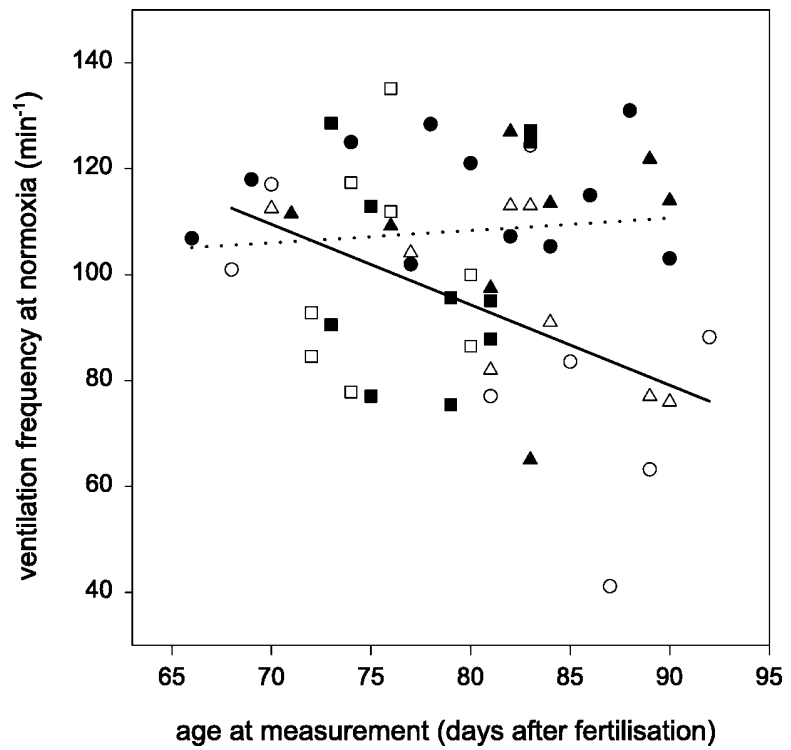

Fig. 3 Ventilation frequency of plaice larvae around the time span of metamorphosis, following exposure to light including UV-B $(n=29$, closed symbols, dotted regression line $)$ or not $(n=23$, open symbols, solid regression line). Each data point represents a single individual from experiments carried out in 1995 (circles), 1996 (triangles) and 1997 (squares). Larvae of the experiments of 1995 and 1996 were irradiated with a UV-B intensity of $0.24 \mathrm{Wm}^{-2}$ and a daily dose of $8.64 \mathrm{kJm}^{-2}$. In 1997, the irradiation conditions were changed to $0.32 \mathrm{Wm}^{-2}$ and $3.46 \mathrm{kJm}^{-2}$

Non-linear ventilation regulation, i.e. linearity quotients of $>0.25$ (Freitag et al. 1998), was found in $20.2 \%$ of the measurements with non UV-B-irradiated plaice larvae compared to $26.4 \%$ of the measurements with UV-B-irradiated larvae. The linearity quotient was found to decrease with age in plaice not exposed to UV-B, indicating an improvement of their respiratory regulation abilities (Fig. 4). Within the same age classification as described above, the average linearity quotients of non UV-B-exposed animals decreased from $0.24 \pm 0.17$ to $0.20 \pm 0.09$ and finally to $0.15 \pm 0.05$. UV-B-exposed animals lacked this trend in the development of respiratory control. Their corresponding mean linearity quotients were $0.33 \pm 0.25,0.17 \pm 0.08$ and $0.34 \pm 0.32$, respectively. Again, in the oldest age class the difference between UV-B-exposed and non UV-B-exposed animals was significant, as the variances were not homogeneous for both groups ( $F$-test).

Plotting linearity quotients against ventilation rates at normoxia (Fig. 5) revealed that non-linear regulation behaviour was more prominent in individuals which already showed a high VF at normoxia. In both UV-B-irradiated and non UV-B-irradiated animals, linearity quotients of $>0.25$ were almost exclusively found in individuals with a VF of $100 \mathrm{~min}^{-1}$ and more.

Oxygen consumption was measured in plaice juveniles exposed for $56 \pm 2$ days to light containing UV-B $\left(0.37 \mathrm{Wm}^{-2}, 4.0 \mathrm{kJm}^{-2}\right.$ daily dose $)$ or not containing UV-B (Fig. 6). At normoxia, a somewhat higher $\dot{\mathrm{M}}_{\mathrm{O}_{2}}$ was measured in the UV-B-irradiated plaice. Due to high 
control animals

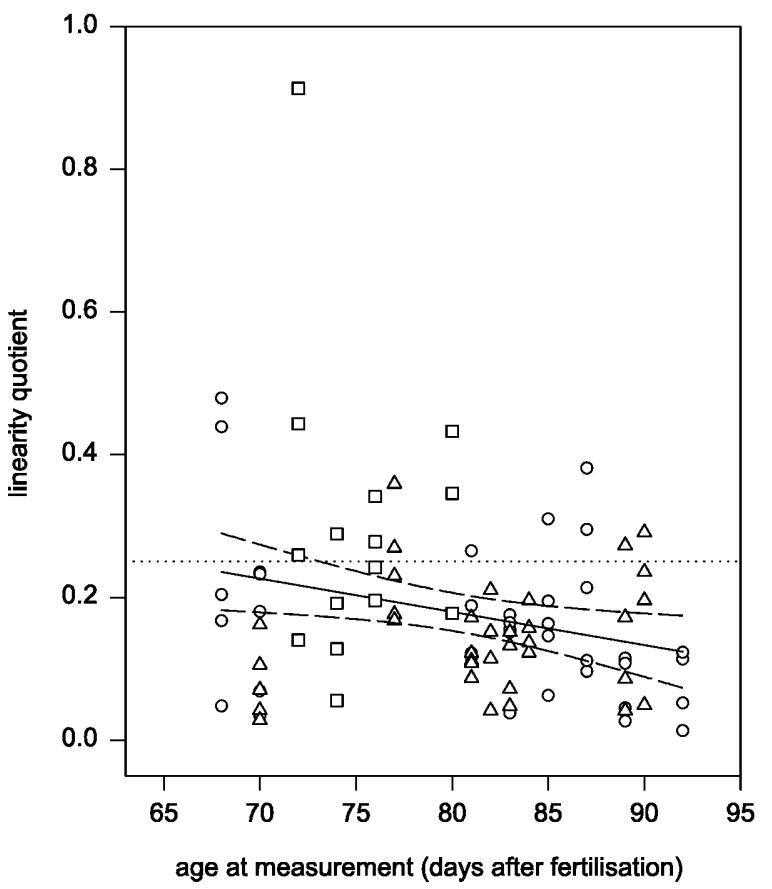

Fig. 4 Precision of respiratory control expressed as linearity quotient in plaice larvae during and after metamorphosis. Decreasing values of the linearity quotient indicate increasing precision of ventilation frequency adjustment during sine-shaped modulations of ambient oxygen partial pressure. Values above the threshold of 0.25 (dotted lines) represent non-linear transmission behaviour, i.e. poor respiratory control. Linearity of respiratory control was
UV-B exposed test animals

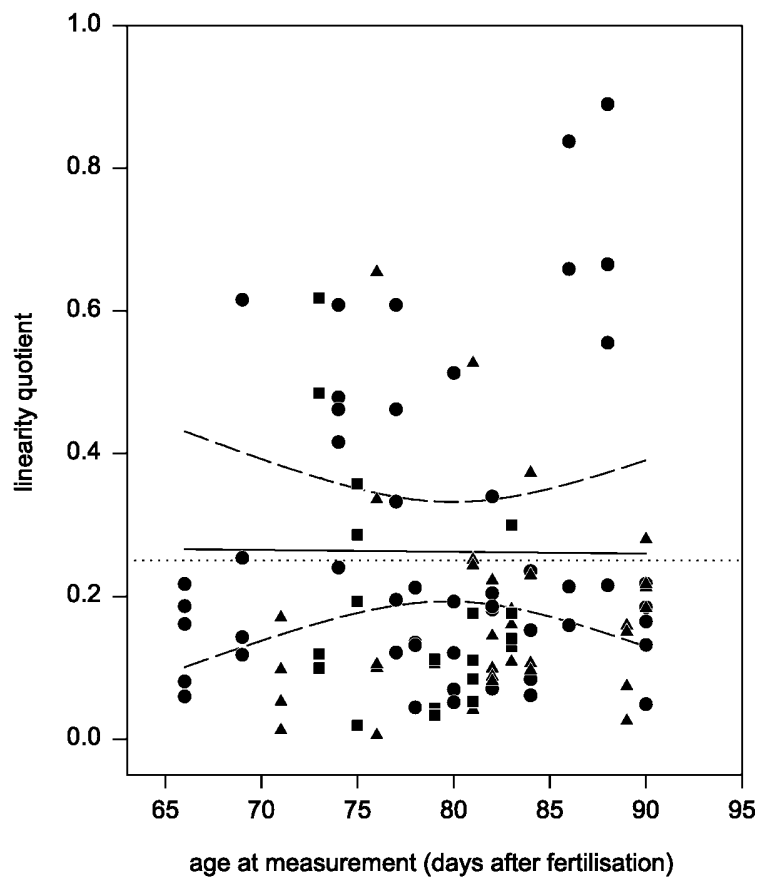

determined in animals after irradiation with light containing UV-B (closed symbols, same animals as in Fig. 3) or not (open symbols, same animals as in Fig. 3). Each larva was investigated 3-5 times with different oxygen modulations of periodic lengths of 3-60 min. Trends in respiratory control development are visualized by regression lines with $95 \%$ confidence intervals (hatched lines) control animals

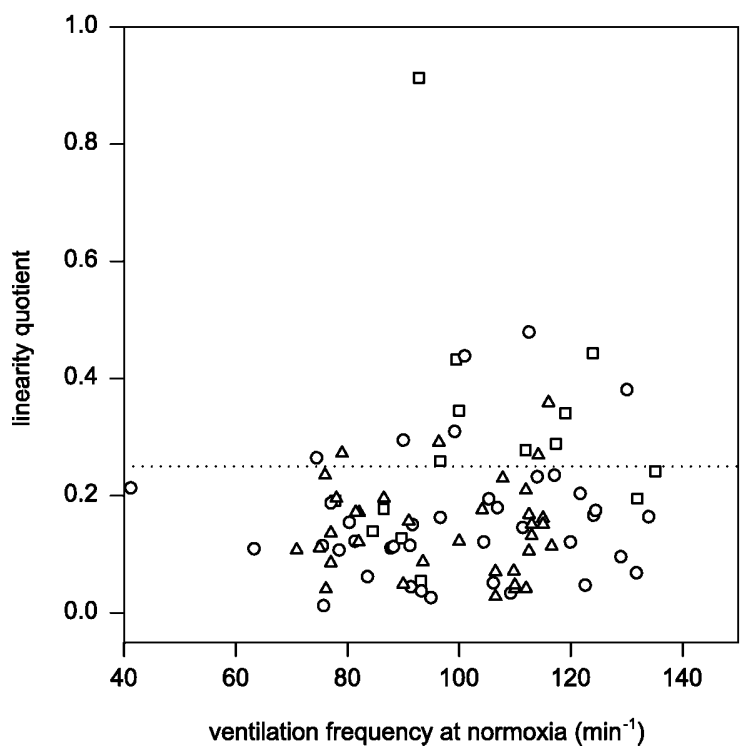

UV-B exposed test animals

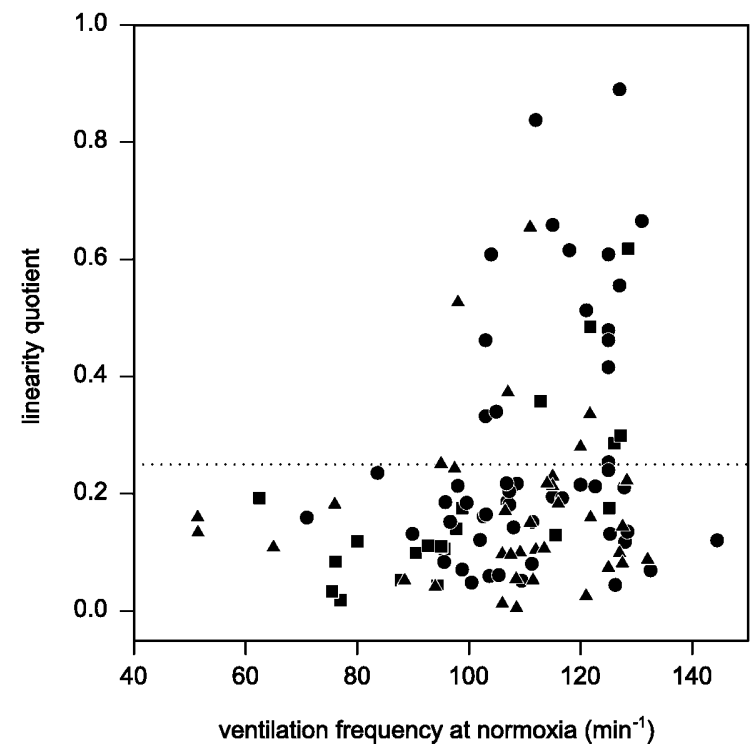

Fig. 5 Linearity quotients of Fig. 4 plotted against the respective animal's ventilation frequency at normoxia. Non-linear regulation behaviour occurred in animals which already showed a high ventilation frequency at normoxia 


\section{control animals}

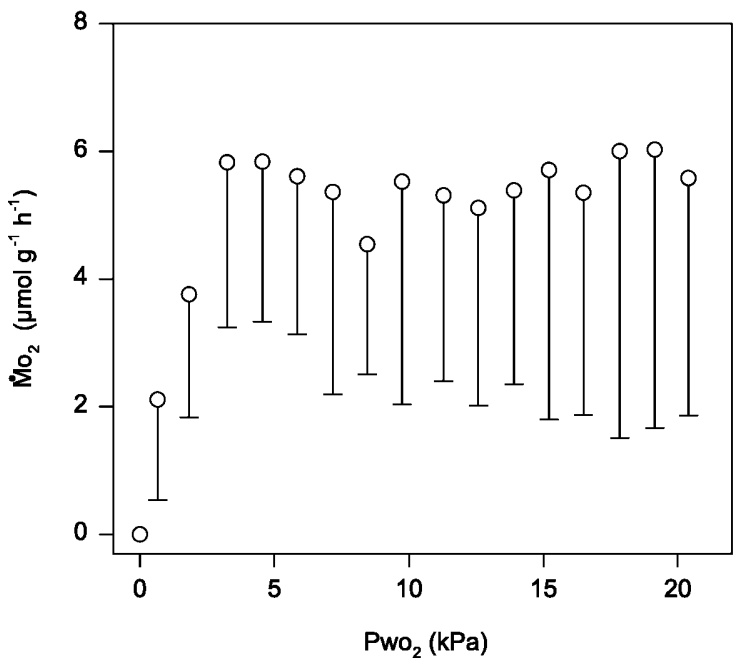

Fig. 6 Mean oxygen consumption rate $\left(\dot{\mathrm{M}}_{\mathrm{O}_{2}}\right)$ and its dependency on oxygen partial pressure $\left(\mathrm{Pwo}_{2}\right)$ in juvenile plaice exposed to light containing UV-B ( $n=4$, mean standard length $23.8 \pm 3.4 \mathrm{~mm}$ ) or not $(n=5$, mean standard length $22.4 \pm 2.9 \mathrm{~mm})$. Differences in $\dot{\mathrm{M}}_{\mathrm{O}}$ between the UV-B test group and the control group were not significant (Student's $t$-test)

SDs, the differences between the oxygen consumption rates of both groups were not significant at any oxygen level.

\section{Discussion}

UV-B radiation is able to induce deleterious effects in aquatic organisms (Siebeck et al. 1994; Zagarese and Williamson 1994; Häder et al. 1995; Häder et al. 1998). In the present study, UV-B radiation caused several adverse effects in plaice offspring ranging from increased mortality and loss of positive buoyancy in embryos to an unusually high ventilation rate as well as impaired respiratory control in larvae and juveniles. A summary of the experimental irradiation conditions and resulting effects determined by our group (this study; Freitag et al. 1998; Steeger et al. 1999) is given in Table 1 and related to the UV-B scenario in the habitat in Fig. 1. The stratospheric ozone levels are thought to be at their minimum at the moment and a further increase in UV-B radiation is not expected (Madronich et al. 1998). An ozone loss of $60 \%$ is unlikely at the northern hemisphere, but UV-B doses in the $30 \%$ ozone-loss range were detected at Carolinensiel on some days in February, March, July and September (Fig. 1). As a result of the use of various detection devices with different spectral sensitivities, UV-B doses reported in the literature vary significantly. The UV-B measurements of this study were not made to represent absolute UV-B levels, but to relate the experimental intensities and doses to the natural situation, as both were measured with the same UV-B detector. A

\section{UV-B exposed test animals}

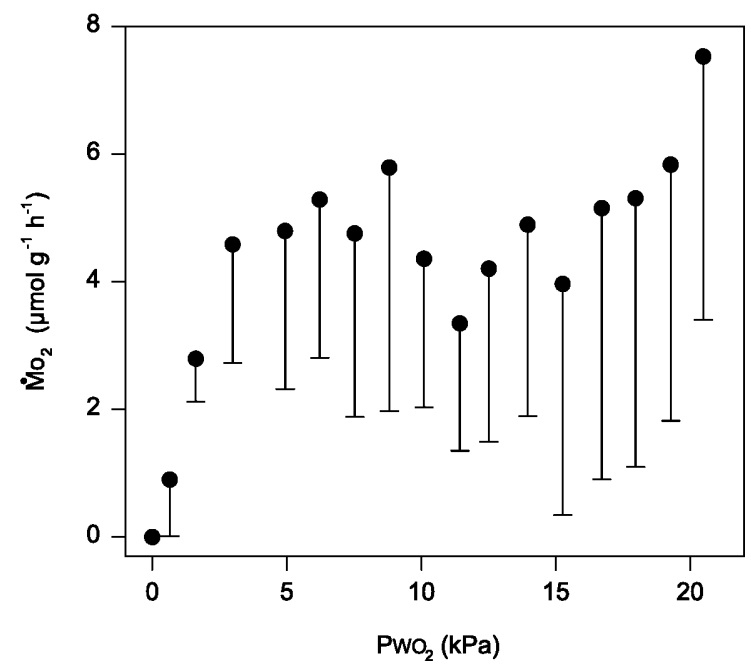

mortality of $100 \%$ as the direct consequence of UV-B irradiation could be induced in plaice offspring. The appropriate intensities and doses, however, exceeded even a UV-B increase of $60 \%$ by far and will obviously be of no ecological importance for plaice populations spawning in the southern North Sea.

Does the predicted UV-B increase endanger North Sea plaice eggs?

The most important parameters modulating UV-B stress are those which result from weather conditions: dangerously high UV-B levels can only arise on sunny and calm days (Németh et al. 1996). When plaice spawn, in early spring, the probability of several days of sunny and calm weather is rather low. For a realistic estimation of the UV-B impact on plaice egg stages it has to be stated that effects which could be induced after several days of irradiation, like high mortality reported by Dethlefsen et al. (1996) and Steeger et al. (1999), are not likely to occur. The UV-B applications of the present study were selected to simulate a more probable situation when plaice eggs are exposed to high UV-B for only 1 or 2 days. Under these conditions, $100 \%$ mortality was not detected (Fig. 2), even after exposure to very high UV-B intensities and doses (3 in Fig. 1). Compared to the controls, somewhat higher and significantly different mortality rates were found after exposure to a daily dose of $6.86 \mathrm{kJm}^{-2}$ and more (Table 1), but again, these doses will not be encountered by North Sea plaice. Under the lowest UV-B-irradiation conditions, which were still higher than those resulting from a further UV-B increase of $60 \%$ in February (1 in Fig. 1), even a positive effect of UV-B irradiation on mortality was observed.

Besides increased mortality, physiological, sublethal effects were detected in plaice embryos (Table 1), including a reduction in heart rate development (Steeger et al. 1999) and loss of positive buoyancy. A slower in- 
Table 1 Experimental ultraviolet-B $(U V-B)$ intensities, doses and related effects of UV-B irradiation on plaice eggs, larvae and juveniles, and juvenile flounder (in one case). $B G$ Before gastrulation, AG after gastrulation

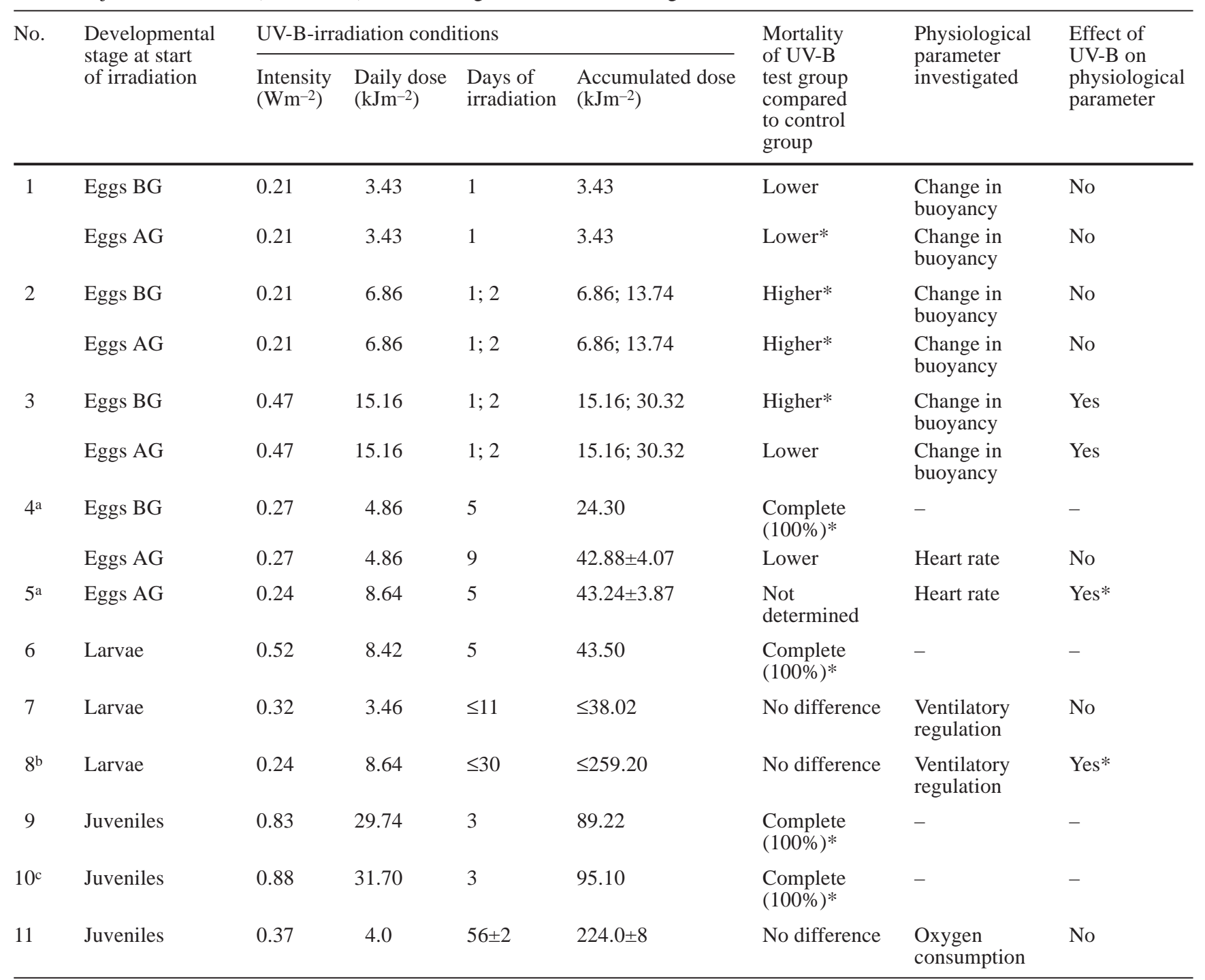

*Effects which were significantly different between UV-B test groups and control groups

a Data from Steeger et al. (1999)

crease in heart rate during embryonic development is typically found in fish embryos exposed to heavy metals or chemical contaminants (von Westernhagen 1988). Loss of positive buoyancy after UV-B irradiation was reported by Dethlefsen et al. (1996). In the present study, this was also observed (Fig. 2), but took place only after irradiation with the highest daily UV-B doses (3 in Fig. 1). Loss of positive buoyancy was obviously caused by UV light in general - including UV-A - for, although to a smaller extent, control groups were affected as well. Loss of positive buoyancy in our experiments was reversible and did not increase mortality. However, this effect may possibly have severe consequences in the habitat. On the other hand, eggs of the halibut (Hippoglossus hippoglossus) respond in this way even to visible light. In this species, light-induced changes in buoyancy are b Data partly from Freitag et al. (1998)

c Specimen: flounder (Platichthys flesus)

discussed as a mechanism enabling the eggs to stay at a certain water depth (Mangor-Jensen and Waiwood 1995). The sublethal effects detected by our group were without exception induced by UV-B-irradiation conditions, which exceeded actual and predicted UV-B levels. From the results of the present study it is concluded that UV-B radiation will not endanger stages of plaice eggs from the southern North Sea.

Plaice populations spawning later in the year, i.e. populations living in regions north of the German Bight, may encounter periods with UV-B intensities and doses which led to deleterious effects in the present study. Moreover, it cannot be said what impact increased UV-B has on other, closely related fish species, which follow one another in spawning throughout the year, like flounder, dab and turbot, with turbot spawning until August. 
Due to the shorter incubation time at increasing water temperatures, the time spent passively at the water surface is shorter the later the species spawn. Although it is reduced to a few days in the case of turbot for instance, the present study showed that even 1 or 2 days of exposure to high UV-B levels may induce damage. Recently, Kouwenberg et al. (1999) investigated UV-B effects on cod eggs from the gulf of St. Lawrence, where cod spawn until late June when solar elevation is maximal. They concluded that $50 \%$ of the eggs located at the water surface would be dead after $42 \mathrm{~h}$ of exposure to current noon surface irradiance measured in August. A further decrease in the ozone layer by $20 \%$ would reduce this time to $32 \mathrm{~h}$.

Does the predicted UV-B increase endanger North Sea plaice larvae and juveniles?

Moderate UV-B irradiation had no effect on mortality of plaice larvae and juveniles (Fig. 1, open rectangles; Table 1), however, sublethal effects on physiological functions could be detected. In larvae irradiated with VIS and UV-A only, ventilation rate decreased during and after metamorphosis. Addition of UV-B to the light spectrum suppressed this effect, and ventilation rates remained at the higher levels (Fig. 3). This could have been due to: (1) retarded development, or (2) a higher metabolic rate, or (3) energy demand (possibly resulting from costs of UV-B-damage repair) in these animals compared to the controls. Evidence of (1) is given by Hunter et al. (1982), who found a significant reduction of growth in anchovy and mackerel larvae after UV-B irradiation and interpreted this as a failure to obtain sufficient food owing to UV damage to sensory or other organ systems. In rainbow trout (Oncorhynchus mykiss), UV-B irradiation of the eye induces damage of the corneal epithelium and corneal stroma (Doughty et al. 1997). (3) is supported by several studies of adult fish. UV-B radiation can lead to skin lesions (Bullock 1982; Berghahn et al. 1993; Blazer et al. 1997), affects mucus production by reducing the number of epithelial goblet cells (Kaweewat and Hofer 1997) and suppresses the functioning of phagocytes and the immune system in general (Salo et al. 1998).

Linear transmission behaviour of respiratory control in the non UV-B-exposed groups was found to increase with age, expressed by decreasing linearity quotients (Fig. 4). This improvement of the ventilatory response to hypoxia at this stage coincides with the shift in habitat from pelagic to benthic, where $\mathrm{Po}_{2}$ is more variable than in the upper water layers of the open ocean. At the sediment surface, oxygen uptake by the sediment decreases oxygen levels in the bottom water to $51 \%$ air saturation in summer and $84 \%$ air saturation in winter (Rasmussen and Jørgensen 1992). Extreme daily changes of $\mathrm{Po}_{2}$ take place in tide pools, where $\mathrm{Po}_{2}$ is increased by photosynthesis during the day and decreased by respiration during the night (Truchot and Duhamel-Jouve 1980; Morris and
Taylor 1983; Bridges et al. 1984). Impairment of the development of respiratory control, detected more often in the UV-B-exposed groups, may not necessarily lead to severe consequences in well-aerated experimental aquaria, but clearly is disadvantageous in nature. Non-linear ventilatory regulation was restricted to larvae which already showed high VFs at normoxia (Fig. 5), thus possibly having not enough scope for a further increase during hypoxia. A more general physiological measure, oxygen consumption rate, was not affected by UV-B irradiation of plaice juveniles (Fig. 6). However, due to the high variance in oxygen consumption between individuals in this experiment, this must be interpreted with caution.

In the course of their development, larvae and juveniles enter the nursery grounds of the Wadden Sea. They gradually reduce their exposure to solar UV-B by switching to a benthic lifestyle in an environment where UV-B attenuation is comparably high due to water turbidity and high gelbstoff concentration. Measurements at the bottom of a residual channel near Carolinensiel at low tide revealed that even in non-turbid water UV-B was attenuated to $1 \%$ of the surface intensity at $10 \mathrm{~cm}$ depth (Steeger, unpublished data). High UV-B levels can furthermore only arise in the course of good weather conditions, low water turbulence and low tide. Considering the probability of a synchronous occurrence of these essential conditions in spring, the probability of days with dangerously high UV-B exposure is low. From the work of Berghahn (1983) and Berghahn et al. (1993), it can be assumed that this may be the case in only 1 or 2 days per month. Although the irradiation conditions employed in the present study (intensities and daily doses) were more realistic in the investigations of larvae and juveniles compared to those with egg stages (Fig. 1), the accumulated doses certainly exceeded those to be expected in nature. It cannot be concluded though that UV-B will have no detrimental effect on North Sea plaice larvae or juveniles. In the field, UV-B stress in combination with a high water temperature led to drastically increased mortality during a single day (Berghahn et al. 1993). Obviously, a prediction of UV-B effects on fish larvae must include interactions with other stressors present in the environment, a situation too complex to be simulated in the laboratory. Besides temperature and other physicochemical parameters, indirect UV-B effects must be considered. The substantial UV-B attenuation in coastal waters for instance is linked to the formation of radical oxygen species, which in turn may raise hydrogen peroxide accumulation in the water to toxic levels (AbeleOeschger et al. 1997).

Acknowledgements We greatly appreciate the donation of fertilized plaice eggs by Dr M. Fonds (NIOZ, Texel, The Netherlands) as well as Q-Panel UVA 340 fluorescent lamps from Pausch Messtechnik (Haan, Germany). We thank J. Blom and U.C. Storz for their valuable help. As a part of the research project "UV und MArine ORganismen" (UV-MAOR), this work was supported by the BMBF (Bundesministerium für Bildung und Forschung, Germany). To catch flounder larvae and measure UV-B intensities at the habitats inside a conservation zone of the Wadden Sea 
National Park of Lower Saxony an authorization (04. 1-2224/ 23-1.6 E) was granted by the National Park Administration. All experiments were carried out with administrative authorization (G76/94) according to the German Law on the Protection of Animals.

\section{References}

Abele-Oeschger D, Röttgers R, Tüg H (1997) Dynamics of UVdriven hydrogen peroxide formation on an intertidal sandflat. Limnol Oceanogr 42(6):1406-1415

Applegate LA, Ley RD (1988) Ultraviolet radiation-induced lethality and repair of pyrimidine dimers in fish embryos. Mutat Res 198:85-92

Bell MG, Hoar WS (1950) Some effects of ultraviolet radiation on sockeye salmon eggs and alevins. Can J Res D28:35-43

Berghahn R (1983) Untersuchungen an Plattfischen und Nordseegarnelen (Crangon crangon) im Eulitoral des Wattenmeers nach dem Übergang zum Bodenleben. Helgol Meeresunters 36:163-181

Berghahn R, Karakiri M (1990) Experimental induction of biological tags in otoliths of 0-group plaice (Pleuronectes platessa) by starvation, temperature and UV-B radiation. Mar Ecol Prog Ser 67:227-233

Berghahn R, Bullock AM, Karakiri M (1993) Effects of solar radiation on the population dynamics of juvenile flatfish in the shallows of the Wadden Sea. J Fish Biol 42:329-345

Björn LO (1989) Computer programs for estimating ultraviolet radiation in daylight. In: Diffey BL (ed) Radiation measurement in photobiology. Academic Press, London, pp 161-189

Blazer VS, Fabacher DL, Little EE, Ewing MS, Kocan KM (1997) Effects of ultraviolet-B radiation on fish: histologic comparison of a UVB-sensitive and a UVB-tolerant species. J Aquat Anim Health 9:132-143

Bridges CR, Taylor AC, Morris SJ, Grieshaber MK (1984) Ecophysiological adaptations in Blennius pholis (L.) blood to intertidal rockpool environments. J Exp Mar Biol Ecol 77: $151-167$

Bullock AM (1982) The effect of UV-B irradiation on the integument of the marine flatfish Pleuronectes platessa L. In: Calkins $\mathbf{J}$ (ed) The role of solar ultraviolet radiation in marine ecosystems. Plenum Press, New York, pp 499-508

Davidson AT (1998) The impact of UVB radiation on marine plankton. Mutat Res 422:119-129

Dethlefsen V, Tüg H, Baumann M, Westernhagen $\mathrm{H}$ von, Herbert A (1996) Experimente über die Wirkung von UV-B auf pelagische Fischembryonen in einem Sonnenscheinsimulator. Inf Fischwirtsch 43:180-186

Doughty MJ, Cullen AP, Monteith-McMaster CA (1997) Aquaeous humor and crystalline lens changes associated with ultraviolet radiation or mechanical damage to corneal epithelium in freshwater rainbow trout eyes. J Photochem Photobiol 41: $165-172$

Dunbar CE (1959) Sunburn in fingerling rainbow trout. Prog Fish Culturist 21:74

Freitag JF, Steeger H-U, Storz UC, Paul RJ (1998) Sublethal impairment of respiratory control in plaice (Pleuronectes platessa) larvae induced by UV-B radiation determined using a novel biocybernetical approach. Mar Biol 132:1-8

Häder D-P, Worrest RC (1991) Effects of enhanced solar ultraviolet radiation on aquatic ecosystems. Photochem Photobiol 53:717-725

Häder D-P, Worrest RC, Kumar HD, Smith RC (1995) Effects of increased solar ultraviolet radiation on aquatic ecosystems. Ambio 24:174-180

Häder D-P, Kumar HD, Smith RC, Worrest RC (1998) Effects on aquatic ecosystems. J Photochem Photobiol B 46:53-68

Haempel O, Lechner H (1931) Über die Wirkung von ultravioletter Bestrahlung auf Fischeier und Fischbrut. Z Vergl Physiol $14: 265-272$
Hamdorf K (1960) Die Beeinflussung der Embryonal und Larvalentwicklung der Regenbogenforelle (Salmo irideus Gibb.) durch Strahlung im sichtbaren Bereich. Z Vergl Physiol 42: $525-565$

Hempel G, Weikert H (1972) The neuston of the subtropical and boreal north-eastern Atlantic Ocean. A review. Mar Biol 13: $70-88$

Hovenkamp F (1991) Immigration of larval plaice Pleuronectes platessa in the western Wadden Sea: a question of timing. Neth J Sea Res 27:287-296

Hunter JR, Taylor JH, Moser HG (1979) Effect of ultraviolet irradiation on eggs and larvae of the northern anchovy, Engraulix mordax, and the pacific mackerel, Scomber japonicus, during the embryonic stage. Photochem Photobiol 29:325-338

Hunter JR, Kaupp SE, Taylor JH (1981) Effects of solar and artificial ultraviolet-B radiation on larval northern anchovy, Engraulix mordax. Photochem Photobiol 34:477-486

Hunter JR, Kaupp SE, Taylor JH (1982) Assessment of effects of UV radiation on marine fish larvae. In: Calkins $J$ (ed) The role of solar ultraviolet radiation in marine ecosystems. Plenum Press, New York, pp 459-497

Kaupp SE, Hunter JR (1981) Photorepair in larval anchovy, Engraulix mordax. Photochem Photobiol 33:253-256

Kaweewat K, Hofer R (1997) Effect of UV-B radiation on goblet cells in the skin of different fish species. J Photochem Photobiol B 41:222-226

Kouwenberg JHM, Browman HI, Cullen JJ, Davis RF, St-Pierre J-F, Runge JA (1999) Biological weighting of ultraviolet (280-400 nm) induced mortality in marine zooplankton and fish. I. Atlantic cod (Gadus morhua) eggs. Mar Biol 134:269284

Madronich S, McKenzie RL, Björn LO, Caldwell MM (1998) Changes in biologically active ultraviolet radiation reaching the Earth's surface. J Photochem Photobiol B 46:5-19

Mangor-Jensen A, Waiwood KG (1995) The effect of light exposure on buoyancy of halibut eggs. J Fish Biol 47:18-25

Morris S, Taylor AC (1983) Diurnal and seasonal variation in physico-chemical conditions within intertidal rockpools. Est Coast Shelf Sci 17:339-355

Németh P, Tóth Z, Nagy Z (1996) Effect of weather conditions on UV-B radiation reaching the earth's surface. J Photochem Photobiol B 32:177-181

Niu X, Frederick JE, Stein ML, Tiao GC (1992) Trends in column ozone based on TOMS data: dependence on month, latitude, and longitude. J Geophys Res 97D:14661-14669

Paul RJ, Colmorgen M, Hüller S, Tyroller F, Zinkler D (1997) Circulation and respiratory control in millimetre-sized animals (Daphnia magna, Folsomia candida) studied by optical methods. J Comp Physiol B 167:399-408

Pommeranz T (1974) Resistance of plaice eggs to mechanical stress and light. In: Blaxter JHS (ed) The early life history of fish. Springer, Berlin Heidelberg New York, pp 397-416

Rasmussen H Jørgensen BB (1992) Microelectrode studies of seasonal oxygen uptake in a coastal sediment: role of molecular diffusion. Mar Ecol Prog Ser 81:289-303

Ryland JS (1966) Observations on the development of larvae of the plaice (Pleuronectes platessa), in aquaria. J Cons Perm Int Explor Mer 30:177-195

Salo HM, Tuula M, Aaltonen S, Markkula E, Jokinen I (1998) Ultraviolet B irradiation modulates the immune system of fish (Rutilus rutilus, Cyprinidae). I. Phagocytes. Photochem Photobiol 67(4):433-437

Siebeck O, Vail TL, Williamson CE, Vetter R, Hessen D, Zagarese H, Little E, Balseiro E, Modenutti B, Seva J, Shumate A (1994) Impact of UV-B radiation on zooplankton and fish in pelagic freshwater ecosystems. Arch Hydrobiol Beih Ergebn Limnol 43:101-114

Smith RC (1989) Ozone, middle ultraviolet radiation and the aquatic environment. Photochem Photobiol 50:459-468

Smith RC, Baker KS (1979) Penetration of UV-B and biologically effective dose-rates in natural waters. Photochem Photobiol 29:311-323 
Steeger H-U, Wiemer M, Freitag JF, Paul RJ (1999) Vitality of plaice embryos (Pleuronectes platessa) at moderate UV-B exposure. J Sea Res 42:27-34

Truchot JP, Duhamel-Jouve A (1980) Oxygen and carbon dioxide in the marine intertidal environment: diurnal and tidal changes in rockpools. Respir Physiol 39:241-254

UNEP (1998) Environmental effects of ozone depletion: 1998 assessment. Executive summary. J Photochem Photobiol B 46: $1-4$

Westernhagen H von (1970) Erbrütung der Eier von Dorsch (Gadus morhua), Flunder (Pleuronectes flesus) und Scholle (Pleuronectes platessa) unter kombinierten Temperatur- und
Salzgehaltsbedingungen. Helgol Wiss Meeresunters 21:21102

Westernhagen $\mathrm{H}$ von (1988) Sublethal effects of pollutants on fish eggs and larvae. In: Hoar WS, Randall DJ (eds) Fish physiology, vol XIA. Academic Press, New York, pp 253-346

Zagarese HE, Williamson CE (1994) Modeling the impacts of UV-B radiation on ecological interactions in freshwater and marine ecosystems. In: Biggs RH, Joyner MEB (eds) Stratospheric ozone depletion/UV-B radiation in the biosphere. NATO ASI series, I 18. Springer, Berlin Heidelberg New York, pp 315-328 